ISSN: 2288-7709 (C) 2020 ICMA. http://www.icma.or.kr doi: http://dx.doi.org/10.20482/jemm.2020.8.1.29

\title{
A Study on the Effects of Economic and Financial Stress on the Satisfaction of Living for the Elderly
}

\author{
Jong-Jin KIM ${ }^{1}$, Kyung-Ho $\mathrm{UM}^{2}$ \\ 1 First Author Manager of Social Economic UNHABITAT, Korea. Tel: +82-2-761-8001. Email: 2001j2kt@hanmail.net \\ 2 Corresponding Author Professor, Department of Social Welfare, Kaya University, Korea. Tel: +82-53-766-5345. Email: \\ ukyungho@naver.com
}

Received: September 13, 2019. Revised: January 2, 2020. Accepted: March 31, 2020.

\begin{abstract}
Purpose - In this study, among the various stresses experienced by single-family senior citizens, we will focus on economic and financial stress and help to comprehend it generally, examine the differences in economic and financial stress and coping behaviors caused by the background variables in the aged group, and verify the variables that affect economic and financial stress, response behavior, and life satisfaction.

Research design, data, and methodology - First of all, frequency analysis and technical statistics were conducted to identify the general characteristics of the elderly (characteristics of demographic sociology, social relationships) and the satisfaction level of life. Secondly, Hierarchical Multiple Regression Analysis was conducted to analyse influential factors on life satisfaction.

Results - looking at the demographic characteristics of the elderly showed that in case the spouse exists, the level of satisfaction in life was shown to be higher.

Next, looking at the characteristics of economic stress showed that the lower the economic stress was, the higher the satisfaction level of life was shown.

Conclusions - Since stress has been identified as the most influential variable in life satisfaction through this study, we believe that economic and financial stress should be studied together as a parameter to find out which factors influence life satisfaction, or studies to reduce stresses for experts and senior party members altogether is also needed.
\end{abstract}

Keywords: Economic Stress, Financial Stress, Satisfaction in Life, Spouse Status

JEL Classification Code: I31, J14, E24, H23

\section{Introduction}

In today's highly competitive environment, many companies are entering the global arena to gain market share and The demographic change that has taken place along with the progressing aging society is the increase of the family form, which the elderly stands separately from their children and form a household independently. In traditional family forms, cohabitation of the older parents and children was considered as normal. However, these days the children's consciousness of supporting for their elderly parents has been weakened, and the senior citizens themselves prefer to live independently from their children as long as economic and financial conditions permit. Due to these social changes and the change of the consciousness of children and elderly themselves, the number of elderly single-family households have been continuingly increasing, as the percentage of the proportion of the

\footnotetext{
* This research study by 2019 Semyung University campus academic research funding.
} 
households that only consists of the elderly to the households that includes the elderly was $19.5 \%$ in 1980 (4.8\% for the elderly single-family households, $10.1 \%$ for the elderly couples), $31.8 \%$ in 1990 (9.5\% for the elderly singlefamily households, $17.5 \%$ for the elderly couples). The number rose to $50.9 \%$ in 2000 (16.8\% for elderly single households, $29.2 \%$ for elderly married couples), and today, $2005,56.9 \%$ (24.4\% for elderly single households, $32.5 \%$ for elderly married couples) of the senior citizens were found to be living separately from their children(Kong, Kim \& Kim, 2017).

The increase in the number of elderly single-family households is not expected to be a temporary phenomenon in the transition period, but is expected to become a general form of household in the future. However, even though the elderly single household is formed by one's voluntary choice, due to the nature of generation the current senior citizens are a generation that were not able to pay much attention to preparing their own retirement plans such as pre-retirement pension and savings, due to their children's education, marriage, and housing. Currently, the economic status of the elderly aged 65 or older is shown as relatively poor compared to other age groups. In 2006, the average monthly income of the elderly couples was 1.16 million won, which is less than half of the 3 million won of non-elderly households. Consumption expenditures of the elderly couples are amounted to 102 million won, and $56.1 \%$ of the total expenditure accounts of food, residential energy, and health care. In other words, essential daily life expenditure accounts for the majority of elderly consumption expenditure. In fact, currently many elderly people are reported to be very anxious about their economic conditions, as for the elderly aged 60 years or older in Korea, the rate of economic and financial instability is shown to be up to $48.6 \%$. Compared to $8.1 \%$ in Germany, $29.3 \%$ in USA, $26.5 \%$ in Taiwan, the percentage appears to be much higher. Furthermore, Korea's current elderly generation was not able to accumulate enough assets for their retirement, due to the heavy burden of their children's education expenses, so therefore retired in a poor financial structure. and did not prepare for golden years. In addition, they cannot hardly expect to receive full pension subsidies from the nation and company, and the increase of the charge for the medical treatments, which was caused by the increase of the elderly population, is limiting the benefits of medical insurance and medical protection. Until now, the research on the stress of the elderly has been concentrated on the analysis of the results according to the direct stress source of the elderly, and only a few previous studies have extensively examined the relationship between stress, coping behavior and life satisfaction. In addition, previous studies have commonly succeeded in pointing out that high incomes and economic, financial stability contribute greatly to the satisfaction of the elderly, but the research that concentrated on the relationship between economic and financial stress, coping behavior and life satisfaction is insufficiently done. Indeed, research on the economic and financial crisis management of households began to be conducted on housewives during the 1997 IMF economic crisis, with studies on the farming households taking lead after 1995. Now the elderly household is turning into a normal elderly family form. Systematic research is required to address and respond to the various problems arising from the process of the aging population's transition to a new family form in our society. Moreover, elderly household is a vulnerable group with dual problems of the aging phenomenon and the lack of economic resources and so, finding out how they are dealing with economic and financial stress and what are the concerning factors will be crucial for the establishment of a realistic senior citizen welfare policy(Chang, Koh, Kang, Kim, Kang, Lee \& Kim, 2005).

Therefore in this study, among the various stresses experienced by single-family senior citizens, we will focus on economic and financial stress and help to comprehend it generally, examine the differences in economic and financial stress and coping behaviors caused by the background variables in the aged group, and verify the variables that affect economic and financial stress, response behavior, and life satisfaction. Through this, we will present measures that can minimize economic and financial stress experienced by the elderly, and provide useful basic data for the development of programs that can help set the direction of welfare policies and solve financial problems, and lead to economic and financial stability of senior citizens. In addition, by examining the variables that affect the satisfaction of the elderly's life, we would like to provide information for the development of programs that enhance life satisfaction, and ultimately contribute to improving the quality of the elderly life.

\section{Theoretical Backgrounds}

\subsection{The Elderly Household's financial stress.}

The stress of financial problems and coping methods were measured by the experience and severity of 20 stressors, including family members, income, financial status, occupation, unemployment, time, health, and housing, and the severity of the stressors was reported in the order of sufficient income to cope with the bill on time, overall financial status, family members' unemployment, and job security(Hahn, 2005). 
While the income is the current situation, finance is something that has been accumulated as a result of income and employment from the past and has reached present. Therefore, it is stressed that the income should be measured separately from finance. It also argued that prices have simultaneous effects on all households in the society because they affect society as a whole, but becquse the size of the effects depends on the characteristics of individual households, they should be considered as an area of that consists economic and financial instability for households(Kim, 2016).

Therefore, economic and financial instability was defined as a state in which economic and financial stability was threatened by events and stimuli within and outside the household, and 5 sub-domain areas of economic, financial stress incidents that generates anxiety were composed of price instability, income instability, job insecurity, financial instability and relative deprivation. As above, studies that have researched the economic and financial stresses of households have difficulty in extracting a common measurement method, as they measure economic and financial stress by various tools and methods, depending on the purpose or perspective of the researchers. In this study, economic and financial stress is defined as 'the strain, pain, and anxiety associated with difficulty of the economic life, as well as experienced by single-family senior citizens', and is sorted into two types of stress ; income/spending stress and asset/debt stress(Law, Wong, \& Song, 2004).

By this, we will investigate the degree of economic and financial stress due to loss of fixed income sources and reduction of the household income, consumption spending needed to maintain single-family households, and limited assets, which is recognized by the single-family senior citizens who have retired,

\subsection{Satisfaction in Life.}

Economic stability greatly contributes to raising the satisfaction of the senior citizens' lives, and economic instability gives them a negative view of psychological anxiety and life. Many studies have shown that economic conditions have a significant static effect on elderly's living satisfaction, quality of marital satisfaction, and psychological wellbeing. Accordingly, the variables which can estimate the economic status of elderly household are selected as total asset, monthly household income, debt status, and whether or not a house is owned(Kim \& Youn, 2015).

Generally, use of debt was reported to have a negative effect on economic welfare or financial satisfaction, but studies regarding the effects on psychological welfare are very limited. However, debt transfers eventually serve as a kind of fixed expenditure, because they burden households that have limited income with interest costs and debt repayments. Therefore, given that it can bring economic burden to households and create an imbalance in consumption patterns, it can be estimated that when above a certain level, it will negatively affect not only the welfare of households but also the psychological side of individuals. After collectively analyzing the researches that have been classified by category, the most frequently addressed coping strategies for economic stress are active coping strategies, which are securing resources through exploration of information and income growth, and passive coping strategies, which are reducing expenditure by reducing the urge to consume and saving(Seo, Yang \& Lee, 2014).

In addition, the role of borrowing has been very important in recent years in households, such as taking out loans through credit cards or financial institutions. Based on the outcomes of the researches above, the study aims to measure the level of economic coping behavior of senior households by classifying the coping behavior of the senior households to reduction of expense, financial management, and the use of employment and labor, and by selfassessing the level of activism of the each coping behavior.

\section{Research method}

\subsection{Collecting research targets and data}

In this study, the Korean Retirement and Income Study (KReIS) of National Pension Service conducted in 2017 was used. The Korean Retirement and Income Study (KReIS) data was used.

The 7th Korean Retirement and Income Study data was surveyed nationwide on 5,254 members of households, with the head of the family aged 50 or older. In this study, personal data were used based on the unique identifying household number to examine the connection between pre-retirement preparation and retirement life.

The subject of this study was thought to be appropriate to look at older households as a common characteristic of the elderly. Based on the view that the retirement confirmation period begins at age 60 , the criteria for the study subjects 
were to be age 60 or older, regarding the general retirement preparation of the elderly retired, and a total of 2,812 people who had completed their retirement were subjects to the final analysis.

\subsection{Operational definition and measurement tools for variables}

\subsubsection{Independent Variable: Economic and Finance Stress}

The economic stress consisted of 16 total questions, consisting of two sub-sections each of financial stress, asset/debt stress, in the income and expenditure stress. The Likert scale consists from 1, which means 'Not at all', to 5, which means 'Absolutely Yes', and higher score means more economic stress.

\subsubsection{Dependent Variable: Satisfaction of Life}

Korean Retirement and Income Study used in this study surveyed areas of social relationship satisfaction to measure the content of retirement.

In order to measure the satisfaction of the subject, the various areas of life are divided into sections of living and interpersonal relationships. As mentioned in the preceding study on life satisfaction, it is an important factor for post-retirement life, and therefore we tried to measure the quantity of life satisfaction. There are 12 questions. Each question consists of a 5-point likert scale of 'very dissatisfied', 'unsatisfactory', 'ordinary', 'satisfied' and 'very satisfied'. In this study, based on the operational definition of retirement of the Korean Retirement and Income Study the elderly who do not engage in economic activities and do not intend to seek a job are selected as subjects of the research, therefore excluding the 'occupation' question, remaining 11 question of the life satisfaction, will be measured as mentioned in the preceding study, classifying the important factors for post-retirement life as 'retirement life satisfaction' and 'retirement relationship satisfaction'.

\subsection{Data analysis}

This study used SPSS 21.0 to analyze the data extracted to look at the factors affecting the satisfaction of the life of a retarded worker as following.

First of all, frequency analysis and technical statistics were conducted to identify the general characteristics of the elderly (characteristics of demographic sociology, social relationships) and the satisfaction level of life.

Secondly, Hierarchical Multiple Regression Analysis was conducted to analyse influential factors on life satisfaction.

\section{A Conceptual Framework for E-commerce Logistics System}

The results of the Hierarchical Multiple Regression Analysis to analyse the factors affecting the satisfaction of life in the elderly's economic and financial stress are shown in Table 1. For model 1 the characteristics of demographic sociology, and for model 2 the characteristics of economic stress factors, such as income and expense was inserted into the regression formula, to look into the influence to the life satisfaction. and for Model 3 , we examined significant increases in explanatory variations by injecting asset and debt, which are financial stresses. Meanwhile, a review of the multicollinearity between independent variables showed that the value of the variance inflation factor (VIF) is close to 1 (1.02 to 1.99) in all three models, therefore no problem with the multicollinearity.

As a result of inserting the demographic characteristics, such as gender, age, presence of a spouse, and the highest level of education in Model 1, the regression formula was shown to be significant $(\mathrm{F}=43.322$, $\mathrm{p}<.001)$, and spouse status $(\mathrm{t}=1.816, \mathrm{p}<.001)$ and education received $(\mathrm{t}=6.043, \mathrm{p}<.001)$ was shown to be the variables that significantly affects the satisfaction of life. In other words, we can understand that if the spouse exists, and the higher the educational background, the higher the satisfaction level of life, and the entered independent variables were found to have $29.8 \%$ explanatory power over life satisfaction.

In model 2 economic stress characteristics such as income and expense were inserted, and the result shows that the regression formula was significant $(\mathrm{F}=25.356, \mathrm{p}<.001)$, and the spouse status $(\mathrm{t}=9.726, \mathrm{p}<.001)$, education received $(\mathrm{t}=3.993, \mathrm{p}<.001)$, and the economic stress $(\mathrm{t}=--4.707, \mathrm{p}<.001)$ has been shown to be the variables that affects the satisfaction of life. This showed that if the spouse exists, the higher the educational background, and the lower the economic stress, the higher the satisfaction level of life, and the entered variables were found to have $34.1 \%$ explanatory power over life satisfaction. 
In model 3 financial stresses regarding asset and debt were inserted, and the result shows that the regression formula is significant $(\mathrm{F}=21.991, \mathrm{p}<.001)$ and the status of spouse $(\mathrm{t}=8.425, \mathrm{p}<.001)$, education received $(\mathrm{t}=2.866$, $\mathrm{p}<.01)$, economic stress $(\mathrm{t}=-3.618, \mathrm{p}<.01)$, and financial stress $(\mathrm{t}=-1.534, \mathrm{p}<.05)$ were found to affect life satisfaction. This shows that if the spouse exists, the higher the educational background, and the lower the financial stress and economic stress, the higher the life satisfaction. This model was also shown to have high explanatory power level of $48.6 \%$. Therefore, it can be seen that the lower the economic and financial stress of the elderly, the higher the satisfaction level of life.

Table 1: An Analysis of the Influence Factors on the Satisfaction of Life of the Elderly with Economic and Financial Stress

\begin{tabular}{|c|c|c|c|c|c|c|c|}
\hline \multicolumn{2}{|r|}{ Variable } & \multirow{2}{*}{$\begin{array}{c}\text { Non } \\
\text { standardizati } \\
\text { on factor }\end{array}$} & \multirow{2}{*}{$\begin{array}{c}\text { Standardizati } \\
\text { on factor } \\
\text { Beta }\end{array}$} & \multirow[t]{2}{*}{$\mathrm{t}$} & \multirow[t]{2}{*}{ VIF } & \multirow[t]{2}{*}{$\mathrm{R}^{2}$} & \multirow[t]{2}{*}{$\mathrm{F}$} \\
\hline & & & & & & & \\
\hline \multirow{5}{*}{$\begin{array}{c}\text { Model } \\
1\end{array}$} & (Constant) & 4.135 & .000 & $26.747 * * *$ & 4.135 & \multirow{5}{*}{.298} & \multirow{5}{*}{$43.322 * * *$} \\
\hline & Gender & .222 & .211 & .244 & 0.222 & & \\
\hline & age & .023 & .026 & .258 & 0.023 & & \\
\hline & Existence of Spouse & 1.448 & .417 & $11.816^{* * *}$ & 1.448 & & \\
\hline & academic background & .806 & .809 & $6.043 * * *$ & 0.806 & & \\
\hline \multirow{6}{*}{$\begin{array}{c}\text { Model } \\
2\end{array}$} & (Constant) & 3.243 & .000 & $9.919 * * *$ & 3.243 & \multirow{6}{*}{. .341} & \multirow{6}{*}{7.999} \\
\hline & Gender & -.836 & -.831 & -1.648 & -0.836 & & \\
\hline & age & .440 & .456 & 1.037 & 0.440 & & \\
\hline & Existence of Spouse & 1.457 & 1.424 & $9.726 * * *$ & 1.457 & & \\
\hline & academic background & .604 & .603 & $3.993 * * *$ & 0.604 & & \\
\hline & Economic Stress & -.551 & -.588 & $-4.707 * * *$ & -0.551 & & \\
\hline \multirow{7}{*}{$\begin{array}{c}\text { Model } \\
3\end{array}$} & (Constant) & 1.641 & .000 & $7.916 * * *$ & 1.641 & \multirow{7}{*}{.486} & \multirow{7}{*}{$21.991 * * *$} \\
\hline & Gender & .440 & .435 & .938 & 0.440 & & \\
\hline & age & .322 & .340 & .953 & 0.322 & & \\
\hline & Existence of Spouse & 1.172 & 1.138 & $8.425 * * *$ & 1.172 & & \\
\hline & academic background & .118 & .118 & $2.866 * *$ & 0.118 & & \\
\hline & Economic Stress & -.479 & -.534 & $-3.618 * *$ & -0.479 & & \\
\hline & Financial Stress & -.053 & -.052 & $-1.534 * *$ & -0.053 & & \\
\hline
\end{tabular}

$* \mathrm{p}<.05, * * \mathrm{p}<.01, * * * \mathrm{p}<.001$

a: Dependent Variables: Satisfaction in Life

\section{Conclusion}

In this study, the Korean Retirement and Income Study (KReIS) of National Pension Service conducted in 2017 was used. The purpose of this study lies in exploring how the economic and financial stress affects the satisfaction of the elderly's lives. Therefore, based on the research results, we will examine the characteristics of the elderly and discuss about social support and practical measures to improve the life satisfaction level.

First of all, looking at the demographic characteristics of the elderly showed that in case the spouse exists, the level of satisfaction in life was shown to be higher. Also, the higher the educational background was, the higher the satisfaction level of life was shown.

Next, looking at the characteristics of economic stress showed that the lower the economic stress was, the higher the satisfaction level of life was shown. This indicates that, since economic stress is the stress on declining income and increasing spending, measures to expand income for senior citizens, or measures to reduce or to support elderly spending are needed, in personal or government policies.

Lastly if you look at the characteristics of financial stress, the lower the financial stress was, the higher the satisfaction level of life was shown. Financial stress appears as the anxiety of increase in debt, reduction in assets and preparedness. The senior citizens in Korea especially lack a lot of awareness or preparedness for their assets because they have fewer opportunities to expand their assets. As shown in previous preceding studies, the greatest 
financial stress for the elderly is the insufficiency of opportunities to expand housing cost as non-housing and the residual loans in-households. Therefore, in conclusion it appears that measures or government policies on plans or supports to stabilize elderly housing and reduce debt for the elderly are needed, due to the stress on house downsizing and expanding expense.

Since stress has been identified as the most influential variable in life satisfaction through this study, we believe that economic and financial stress should be studied together as a parameter to find out which factors influence life satisfaction, or studies to reduce stresses for experts and senior party members altogether is also needed.

Accordingly, the following proposals are proposed: Significant differences between groups were expressed depending on the background variable. Depending on the total assets and income sources, there are differences in the economic stress of elderly single-family households, in which social security or property income is a major part of the economic welfare. The income as such can be obtained through assets formed throughout their lives, rather than be determined by current or recent factors. Moreover, in Western welfare countries, senior citizens benefit from the established social security system, which serves to ease the economic gap between the elderly but in Korea, senior citizens hardly benefits from the social security system. Therefore, it is highly likely that differences in job status, income level and asset size before retirement will persist even after retirement, and thus institutional supporting measures, such as compensating the pension system and supporting living expenses should be devised to reduce the gap between classes that disrupt the economic welfare of senior citizens. Also, the economic stress of the retired elderly single-family households differed depending on the level of preparation for the post-retirement, which shows that to prepare for the post-retirement economically is highly important. Therefore, it is necessary to create a program for senior citizens to support asset management and economic life as a welfare, as well as an value-based education program for middle-aged households with retirement upcoming, that can grow awareness of the need and importance of preparing for the retirement age.

\section{References}

Bandura, A. (1977). Self-efficacy: Toward a unifying theory of behavioral change. Psychological Review, 84(2), 191.

Baron, R. M., \& Kenny, D. A. (1986). The moderator-.mediator variable distinction in social psychological research: Conceptual, strategic, and statistical considerations. Journal of Personality and Social Psychology, 51(6), 1173.

Chang, S. J., Koh, S. B., Kang, D., Kim, S. A., Kang, M. G., Lee, C. G., \& Kim, J. W. (2005). Developing an occupational stress scale for Korean employees. Korean Journal of Occupational and Environmental Medicine, 17(4), 297-317.

Choo, M. J. (2015). Effects of Traditional Market Service Quality Factors on Customer Value, Relational Quality, and Behavioral Intention. Journal of Distribution Science, 13(11), 79-92.

Doey, L., \& Kurta, J. (2011). Correspondence analysis applied to psychological research. Tutorials in Quantitative Methods for Psychology, 7(1), 5-14.

Hahn, J. H. (2005). Job motivations, job characteristics, work-family conflict and stress: The case of salesmen in the insurance industry. Journal of Insurance Studies, 16(3), 3 -31.

Hwang, J. M. (2010). Analysis of Multicultural Acceptability in Korea: From the perspective of new politics of membership. The Journal of Asiatic Studies, 53(4), 152-184.

Kong, L., Kim, H. G., \& Kim, Y. J. (2017). The moderating effects of salesperson's cultural intelligence in intercultural sales encounters. The Journal of Distribution Science, 15(12), 85-94.

Kim, J. J. (2014). A Study on the Effects of Traditional Market Healing Stories for Social Integration: Focused on traditional market in Seongnam-si, Gyeonggi-do. Journal of Social Contribution, 1(1), 2-5. 
Kim, J. J. (2014). A Study on the Role of the Leader in the Organizational Life for the Social Integration and the Changing Consciousness among the Traders: Focused on traditional market in Seongnam-si, Gyeonggi-do. Journal of Social Contribution, 1(2), 6-10.

Kim, J. J. (2015). The Negative Impact Study on the Information of the Large Discount Retailers. Journal of Distribution Science, 13(7), 33-40.

Kim, J. J. (2016). A Study on the Change of Conscious Thinking Process and Moral Reasoning in Social Welfare. Journal of Social Contribution. 3(1), 2-6.

Kim, J. J., \& Youn, M. K. (2015). Correlation analysis of self-employment of retirees using demographic characteristics of the retail establishment. International Journal of Industrial Distribution \& Business, 6(4), $17-$ 22.

Kim, J. J., Eom, T. K., Kim, S. W., \& Youn, M. K. (2015). Effects of Ethical Management on Job Satisfaction and Turnover in the South Korean Service Industry. International Journal of Industrial Distribution \& Business, 6(1), 17-26.

Kim, H. S., \& Lee, S. C. (2014). Measuring Multiculture Acceptance by Skewed Interest in Regions: A Case Study of Dalseo-gu, Korea. Local administration Studies, 28(1), 89-114.

Law, K. S., Wong, C. S., \& Song, L. J. (2004). The Construct and Criterion Validity of Emotional Intelligence and Its Potential Utility for Management Studies. Journal of Applied Psychology, 89(3), 483-496.

Lee, K. H., \& Song, J. S. (2010). The effect of emotional intelligence on self-efficacy and job stress of nurses. Journal of Korean Academic Nurse, 16(1), 17-25.

Menon, S., \& Kahn, B. E. (2003). Corporate Sponsorships of Philanthropic Activities: When Do They Impact Perception of Sponsor Brand?. Journal of Consumer Psychology, 13(3), 316-327.

Seo, J. S., Yang, J. J., \& Lee, Y. G. (2014). Effects of Perceived Benefits and Costs of Traditional Market Support on Relationship Quality and Support. Journal of Distribution Science, 12(12), 43-54.

Sung, H. W., Kim, J. J., \& Youn, M. K. (2014). A Study upon Effects of Family Restaurant Consumption Values upon Satisfaction, Reliability and Behavioural Intentions in Korea: Focused on College Students at Metropolitan Area. Journal of Asian Finance, Economics and Business, 1(4), 29-37.

Yoon, I. J., \& Alexander, N. (2009). Brand Authentication: Creating and Maintaining Brand Auras. European Journal of Marketing, 43(3), 551-562. 